\title{
Prospecção de descritores para seleção de genótipos de amendoim tolerantes a pragas de grãos armazenados
}

\author{
Roseane C. Santos ${ }^{1}$, Lucas N. da Luz ${ }^{2}$, Morganna P. N. Pinheiro ${ }^{3}$, \\ Antonio L. de A. Galvão Filho ${ }^{4}$ \& Liziane M. de Lima ${ }^{5}$ \\ ${ }^{1}$ Embrapa Algodão. Campina Grande, PB. E-mail: roseane.santos@embrapa.br (Autor correspondente) \\ ${ }^{2}$ UFCA. Crato, CE. E-mail: lucasluzbreeder@gmail.com \\ ${ }^{3}$ UFRPE. Recife, PE. E-mail: morgannapollynne@yahoo.com.br \\ ${ }^{4}$ Embrapa Algodão. Campina Grande, PB. E-mail: antonio.arroxelas@embrapa.br \\ ${ }^{5}$ Embrapa Algodão. Campina Grande, PB. E-mail: liziane.lima@embrapa.br
}

Palavras-chave:

Arachis hypogaea

inibidor de tripsina e quimotripsina

melhoramento genético

controle de pragas

\begin{abstract}
R E S U M O
As inter-relações entre descritores bioquímicos e agronômicos foram investigadas em genótipos de amendoim visando identificar indicadores de seleção para tolerância a pragas de grãos armazenados, com base na capacidade inibitória para tripsina e quimotripsina. Dez genótipos foram cultivados em campo, em 2011/2012, e suas sementes utilizadas para os ensaios bioquímicos. Quatro descritores agronômicos foram utilizados para compor as análises de correlação. Sete genótipos revelaram alta capacidade inibitória para tripsina, com mais de $80 \%$ de inibição; contudo, para quimotripsina, observou-se baixa inibição em todos os genótipos, variando entre 4 e $12 \%$. Nas análises de correlação não foram observadas inter-relações significativas entre os inibidores e as demais variáveis, com exceção de inibidor de tripsina x proteínas nas folhas, que revelou correlação negativa de alta magnitude indicando que alto teor de proteínas nas folhas pode reduzir o nível de inibidor de tripsina nas sementes. Este descritor poderia ser utilizado como indicador de seleção para tolerância a pragas de grãos armazenados, com o benefício de não destruir a semente.
\end{abstract}

Key words:

Arachis hypogaea

trypsin and chymotrypsin inhibitor breeding

pest control

\section{Prospecting of descriptors for selection of peanut genotypes tolerant to stored grain pests}

\begin{abstract}
A B S T R A C T
The interrelations between biochemical and agronomic descriptors were investigated in peanut genotypes in order to identify selection indicators for tolerance to stored grain pests, based on the inhibitory capacity for trypsin and chymotrypsin. Ten genotypes were grown in field, in 2011/2012, and their seeds were further used for biochemical assays. Four agronomic traits were used in order to compose the correlation analysis. Seven genotypes showed high inhibitory capacity for trypsin with more than $80 \%$ inhibition; however, chymotrypsin inhibition was low in all genotypes, varying between 4 and 12\%. No significant interrelationships between inhibitors and the other variables were seen in correlation analysis, except trypsin inhibitor $\mathrm{x}$ leaves protein, which revealed a negative correlation with high magnitude, indicating that a high protein content in the leaves can reduce the level of trypsin inhibitor in the seeds. This descriptor could be used as a selection indicator for tolerance to stored grain pests, adding the benefit of saving the seed.
\end{abstract}

\section{INTRODUÇÃ̃o}

Os insetos-praga estão entre os principais problemas relacionados à perda de produtividade em várias culturas. Por meio do melhoramento convencional a obtenção de cultivares resistentes é mais complexa em razão dos vários fatores genéticos que envolvem a resistência ao inseto. Para algumas pragas, porém, como as de grãos armazenados, a obtenção de resistência é mais exequível em virtude das várias proteínas de defesa, encontradas naturalmente nas sementes de algumas espécies vegetais, em especial das Solanaceae e Leguminosae (Habib \& Fazili, 2007; Oliveira et al., 2009).
Proteínas de defesa têm sido reportadas na literatura, entre elas os inibidores proteicos (IPs), quitinases, proteínas inativadoras de ribossomo (RIPs), arcelinas, vicilinas, leguminas, lectinas, defensinas, tioninas e proteínas de transferências de lipídeos (LTPs) (Habib \& Fazili, 2007; Pereira et al., 2007; Hartl et al., 2011; Lima \& Morais, 2013). Esses inibidores formam um complexo inibindo, parcial ou totalmente, suas enzimas cognatas (Habib \& Fazili, 2007) e exercem papel preponderante no melhoramento de plantas para resistência a insetos, tanto por meio convencional quanto biotecnológico, em razão da sua capacidade de inibir enzimas hidrolíticas (Pereira et al., 2007; Oliveira et al., 2009; De Paola et al., 2012). 
Vários autores reportam que os IPs (proteases e $\alpha$-amilases) atuam como defensivos naturais contra insetos, principalmente das Ordens Lepidoptera e Coleoptera, em razão dos efeitos deletérios provocados, incluindo redução de fecundidade, perda de peso, aumento da mortalidade e algumas deformações, em virtude da redução da atividade proteolítica do trato digestivo, limitando a assimilação de nutrientes (Haq et al., 2004; Silva et al., 2006; Macedo et al., 2010). Isto demonstra o potencial do uso desses metabólitos como ferramenta para seleção de plantas resistentes a pragas (Chye et al., 2006; Mosolov \& Valueva, 2008).

O aumento na expressão dos IPs nos tecidos vegetais está relacionado a danos nos tecidos de armazenamento, como os provocados por alimentação de insetos (Zavala et al., 2004) o que possibilita a condução de estudos envolvendo prospecção de IPs em tecidos de reserva com enfoque em espécies leguminosas e posterior investigação sobre seu potencial de inibição em ensaios in vitro e in vivo contra enzimas digestivas de insetos-praga.

Entre as espécies detentoras de IPs nas sementes, cita-se o amendoim, uma leguminosa de ciclo curto e com teores variados de proteínas nas sementes (Santos et al., 2010; Freire \& Suasssuna, 2009). Inibidores de tripsina e quimotripsina em amendoim têm sido estudados quanto à sequência de aminoácidos, mecanismos de inibição, estrutura cristalina e domínios de ligação (Norioka \& Ikenaka, 1983; 1984; Dodo et al., 2004).

Em trabalhos de melhoramento a prospecção de linhagens ricas em IPs se constitui em excelente ferramenta para seleção de genótipos com potencial de resistência a pragas de grãos armazenados. Como a análise é feita por meio destrutivo da semente, as seleções se tornam inviáveis em populações segregantes que são as de maior variabilidade no início dos trabalhos de melhoramento havendo, contudo, descritores fenotípicos ou bioquímicos que possam estar associados a este caráter, a seleção pode tornar-se facilitada, contribuindo para o progresso do melhoramento de forma efetiva, sem prejuízo de descarte de linhas promissoras.

Com o exposto, objetivou-se com este trabalho prospectar descritores bioquímicos e agronômicos com potencial para contribuir na seleção de genótipos de amendoim tolerantes a pragas de grãos armazenados, baseando-se em análises simples e de correlação.

\section{MATERIAl E MÉtodos}

Dez genótipos de amendoim, constituídos por oito linhagens avançadas e duas cultivares, foram cultivados em Barbalha $\left(7^{\circ}\right.$ $18^{\prime} 18^{\prime \prime} \mathrm{S} ; 39^{\circ} 18^{\prime} 07^{\prime \prime} \mathrm{W}$; altitude $414 \mathrm{~m}$ ), durante o período de fevereiro a maio de 2011/2012. O solo, caracterizado como Vertissolo, de textura franco-arenosa, foi previamente corrigido e adubado em razão da recomendação de análise do solo. As parcelas foram constituídas de três fileiras de 6 $\mathrm{m}$, espaçadas entre si em $0,7 \mathrm{~m}$. O espaçamento entre plantas foi de $0,2 \mathrm{~m}$ deixando-se apenas duas plantas/cova. A fileira central foi considerada área útil para a coleta dos dados. $\mathrm{O}$ delineamento experimental adotado foi blocos ao acaso com cinco repetições. O manejo dos genótipos seguiu de acordo com as recomendações descritas por Santos et al. (2006).

A colheita foi iniciada aos 85 dias para os materiais mais precoces e até os 110 dias para os mais tardios (Tabela 1). As médias de temperatura e umidade relativa do ar foram, durante o experimento, de $35{ }^{\circ} \mathrm{C}$ e $72 \%$, respectivamente. O total de precipitação pluvial durante o ano foi $1.160 \mathrm{~mm}$. A descrição da genealogia e de alguns descritores agronômicos dos genótipos avaliados se encontra na Tabela 1. As variáveis agronômicos avaliadas foram altura da haste principal, comprimento de semente, peso de 100 sementes e número de vagens/planta.

Após as etapas de pós-colheita, quando as sementes se encontravam com 8 a $10 \%$ de umidade, foram procedidas as análises bioquímicas para as seguintes variáveis: teor de óleo nas sementes, carboidratos e proteínas nas folhas. Adicionalmente, foram analisados os teores de inibidores de tripsina e quimotripsina nas sementes.

O teor de óleo foi estimado por meio de Ressonância Magnética Nuclear (RMN), realizado no Laboratório de Química Avançada da Embrapa Algodão, a partir de 100 g de amostras selecionadas ao acaso. Para as análises de proteínas totais e carboidratos, o extrato bruto foi obtido de folhas frescas, na concentração de $20 \%$ em tampão fosfato de potássio monobásico $100 \mathrm{mM}$, EDTA 0,1 mM, pH 7,0, seguindo metodologia descrita por Pereira et al. (2012). A concentração das proteínas totais foi determinada pelo método de Bradford (1976) e a leitura realizada a $595 \mathrm{~nm}$. A determinação dos carboidratos seguiu metodologia do fenol ácido sulfúrico, descrita em Dubois et al. (1956). A leitura foi procedida a $490 \mathrm{~nm}$. Todas as análises foram feitas com cinco repetições, cada uma em triplicata.

Para determinação da atividade dos inibidores de tripsina e quimotripsina, foram triturados $10 \mathrm{~g}$ de sementes de cada genótipo de amendoim em multiprocessador, com posterior delipidação com $20 \mathrm{~mL}$ de acetona PA e $20 \mathrm{~mL}$ de hexano PA, obedecendo metodologia descrita por Bland \& Lax (2000); em seguida, foram pesados $100 \mathrm{mg}$ da amostra delipidada e acrescentado $1 \mathrm{~mL}$ de tampão Tris-HCl $50 \mathrm{~mol} \mathrm{~L}^{-1}$, pH 8,5, incubado sob agitação durante a noite, a $4^{\circ} \mathrm{C}$. O extrato foi

Tabela 1. Descrição da genealogia e de alguns descritores agronômicos dos genótipos de amendoim investigados neste estudo

\begin{tabular}{|c|c|c|c|c|c|c|c|}
\hline Genótipo & Subesp. & Genealogia & GB & $\mathrm{HC}$ & C & TS & CS \\
\hline BR 1 & $\mathrm{~F}$ & Cultivar & $\mathrm{Va}$ & $\mathrm{E}$ & 87 & $M$ & V \\
\hline LViPe-06 & $\mathrm{H}$ & Top line & Vi & $\mathrm{R}$ & 120 & $E G$ & B \\
\hline 55437 & V & Cultivar & Sp & $E$ & 85 & $P$ & B \\
\hline Moita & $\mathrm{F}$ & $\mathrm{F}_{5} / 6(\mathrm{BR} 1 \mathrm{xLViPe})$ & Va & $M$ & 100 & M & $\mathrm{Br}$ \\
\hline Gen.20 & $\mathrm{F}$ & $\mathrm{F}_{5} / 6(\mathrm{BR} 1 \times \mathrm{LViPe})$ & $\mathrm{Va}$ & SE & 100 & $M$ & V \\
\hline Gen.46 & $\mathrm{H}$ & $\mathrm{F}_{5 / 6}(\mathrm{BR} 1 \times \mathrm{LViPe})$ & $\mathrm{Va}$ & $M$ & 110 & $M$ & V \\
\hline Gen.59 & $F$ & $\mathrm{~F}_{5} / 6(\mathrm{BR} 1 \mathrm{xLViPe})$ & $\mathrm{Va}$ & $M$ & 100 & M & B \\
\hline Gen.67 & $\mathrm{H}$ & $\mathrm{F}_{5} / 6(\mathrm{BR} 1 \times \mathrm{LViPe})$ & $\mathrm{Va}$ & SE & 90 & $M$ & B \\
\hline Gen.73 & $\mathrm{H}$ & $\mathrm{F}_{5} / 6(\mathrm{BR} 1 \times \mathrm{LViPe})$ & $\mathrm{Va}$ & SE & 90 & $M$ & B \\
\hline Gen.108 & $\mathrm{H}$ & $\mathrm{F}_{5} / 6(\mathrm{BR} 1 \times \mathrm{LViPe})$ & $\mathrm{Va}$ & SR & 115 & G & $\mathrm{Br}$ \\
\hline
\end{tabular}

Subsp. - Subespécie: F - Fastigiata, H - Hypogaea, V - Vulgarias; GB - Grupo botânico: Va - Valencia, Vi - Virginia, Sp - Spanish; HC - Hábito de crescimento: E - Ereto, R - Rasteiro, M Moita, SE - Semiereto, SR - Semirasteiro; C - Ciclo; TS: Tamanho da semente: P - Pequena, M - Média, G - Grande, EG - Extra grande; CS - Cor da semente: V - Vermelha, B - Bege, Br - Branca 
centrifugado a $12.000 \mathrm{x}$ g por $20 \mathrm{~min}$ a $4^{\circ} \mathrm{C}$ e o sobrenadante coletado denominado extrato bruto (EB).

A atividade inibitória foi determinada incubando-se alíquotas de $5 \mu \mathrm{g}$ de tripsina bovina ou $5 \mu \mathrm{g}$ de quimotripsina com $69 \mu \mathrm{L}$ de tampão Tris- $\mathrm{HCl} 50 \mathrm{~mol} \mathrm{~L}^{-1} \mathrm{pH} 8,5$ ou Tris- $\mathrm{HCl}$ $100 \mathrm{mM} \mathrm{pH}$ 7,8, respectivamente, e $5 \mu \mathrm{g}$ de EB. A reação foi pré-incubada a $37^{\circ} \mathrm{C}$, durante $20 \mathrm{~min}$. Adicionados $100 \mu \mathrm{L}$ da solução do substrato de azocaseína a 1,5\% (m/v) e incubados por mais $20 \mathrm{~min}$. No final desse tempo foram adicionados $100 \mu \mathrm{L} \mathrm{da}$ azocaseína nos negativos da atividade e a reação foi parada com $150 \mu \mathrm{L}$ de solução de ácido tricloracético (TCA 20\%). Após 5 min em temperatura ambiente, as amostras foram centrifugadas a $12.000 \mathrm{x}$ g por $10 \mathrm{~min}$. Alíquotas de $250 \mu \mathrm{L}$ do sobrenadante foram coletadas e adicionadas a $250 \mu \mathrm{L}$ de $\mathrm{NaOH} 2 \mathrm{~mol} \mathrm{~L}^{-1} \mathrm{e} \mathrm{a}$ absorbância medida a $440 \mathrm{~nm}$. Os ensaios foram realizados em triplicata autêntica, seguindo-se a metodologia estabelecida por Oliveira et al. (2002).

Após compatibilização dos dados procederam-se às análises de variância e de correlação através do aplicativo computacional GENES, versão 2009.7.0 (Cruz, 2006).

\section{Resultados e Discussão}

Verificou-se diferença estatística significativa entre os genótipos para todas as variáveis utilizadas neste estudo indicando que para todas elas há resposta diferencial útil para ser utilizada em trabalhos de seleção (Tabela 2).

Ao se considerar que entre as variáveis estudadas as de maior interesse para seleção de tolerância a pragas de grãos armazenados, são IT e IQ, nas Figuras $1 \mathrm{~A}$ e B, estão apresentadas, respectivamente, as atividades inibitórias dos genótipos estudados. Observou-se que os genótipos apresentaram inibição e variaram de 45 a $92 \%$ e 4 a $12 \%$ para tripsina e quimotripsina, respectivamente. Embora os percentuais encontrados para IQ tenham sido relativamente baixos, é possível esperar que uma combinação dos maiores níveis de IQ e IT possa favorecer a potencialidade do genótipo para controlar o inseto-alvo nas sementes. Neste aspecto, o investimento nas linhagens P20 e P67, como progenitores para tolerância a pragas de grãos armazenados, parece ser promissor, visto que ambas superam os percentuais de $90 \%$ de inibição para IT e 10\% para IQ. Tal

Tabela 2. Resumo da análise de variância para descritores bioquímicos e agronômicos do amendoim

\begin{tabular}{|c|c|c|c|c|c|c|c|c|c|c|}
\hline \multirow[b]{2}{*}{ FV } & \multirow[b]{2}{*}{ GL } & \multicolumn{9}{|c|}{$\mathbf{Q M}$} \\
\hline & & IQ & IT & $\overline{\mathrm{AH}}$ & PS & CS & 0 & $\mathrm{Vg} / \mathrm{PI}$ & $\mathrm{CH}$ & $\mathbf{P f}$ \\
\hline $\mathrm{Bl}$ & 4 & 0.01 & 1.5 & 6.5 & 2.1 & 0.04 & 0.6 & 12.7 & 61.4 & 1.2 \\
\hline $\mathrm{G}$ & 9 & $0.07^{\star}$ & $46.9^{*}$ & $382.2^{*}$ & $559^{*}$ & $0.63^{*}$ & $23.9^{*}$ & $165.2^{*}$ & $308.1^{*}$ & $18.4^{\star \star}$ \\
\hline $\mathrm{R}$ & 36 & 0.08 & 1.4 & 2.8 & 1.0 & 0.03 & 0.5 & 8.6 & 35.1 & 5.3 \\
\hline$M$ & & 0.53 & 17.6 & 35.7 & 49.8 & 1.23 & 47.0 & 21.8 & 50.6 & 691 \\
\hline CV & & 17.8 & 6.72 & 4.7 & 1.9 & 4.89 & 1.5 & 13.4 & 11.7 & 10.5 \\
\hline
\end{tabular}

** * Significativo a 0,01 e 0,05 respectivamente, pelo teste $\mathrm{t}$

FV - Fonte de variação, GL - Grau de liberdade, QM - Quadrado médio, BI - Bloco, G - Genótipo, R - Resíduo, M - Média, CV - Coeficiente de variação, IQ - Inibidor de quimotripsina, IT - Inibidor de tripsina, AH - Altura da haste principal, PS - Peso de 100 sementes, CS - Comprimento de semente, 0 - Teor de óleo na semente; Vg/PI - vagem/planta, $\mathrm{CH}$ - Teor de carboidratos nas folhas, Pf - Teor de proteínas totais nas folhas
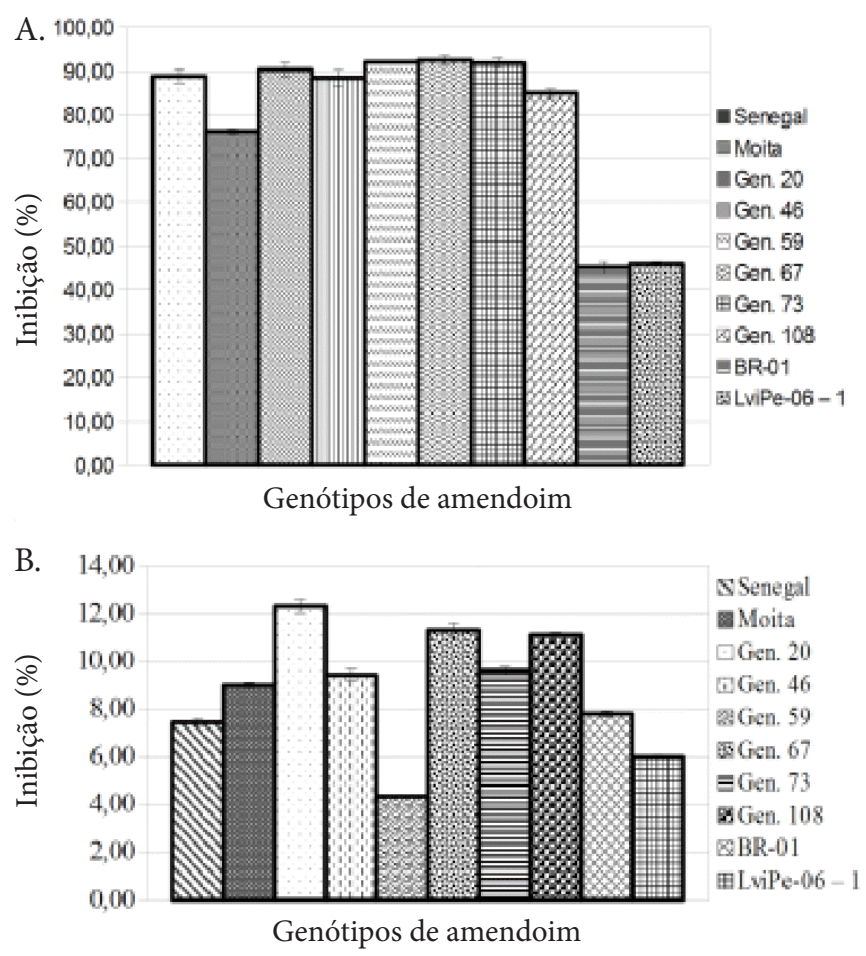

Barra em cada genótipo indica desvio padrão

Figura 1. Atividade inibitória para (A) tripsina (IT) e (B) quimotripsina (IQ) em sementes de amendoim

inferência se baseia em resultados de estudos conduzidos por Martins (2013), que procederam ao bioensaio de alimentação com Alphitobius diaperinus alimentados com grãos de amendoim previamente selecionados quanto à alta inibição de tripsina, verificando redução na taxa de eclosão dos insetos entre 42 e $51 \%$.

Um fator que deve ser considerado neste resultado, é que os genitores que geraram as linhagens P20 e P67, LViPe e BR1, apresentaram média de $45 \%$ para IT e $6 \%$ para IQ, configurando tendência de ação gênica sobredominante com percentuais na ordem de $50 \%$ acima dos genitores, para IT e $40 \%$ para IQ. No aspecto genético este resultado pode estar associado à combinação dos vários genes de IPs presentes nos genitores. Tal justificativa se baseia no fato de que, no presente estudo, a detecção de IPs foi feita no extrato bruto das sementes. Sabe-se, no entanto, através da literatura, que famílias de IPs em leguminosas envolvem vários genes, alguns com padrão de expressão mendeliana ou com efeitos pleiotrópicos (Dunaevsky et al., 2005; Oliveira et al., 2009; De Paola et al., 2012). No amendoim pelo menos sete IPs já foram identificados (Norioka et al., 1983; Dodo et al., 2004; Serquiz, 2012), mas não se sabe ainda qual a inter-relação da expressão desses genes nas composições de linhagens geradas a partir de populações intraespecíficas, como é o caso das linhagens utilizadas neste estudo.

As estimativas dos coeficientes de correlação entre os descritores bioquímicos e agronômicos se encontram na Tabela 3. Entre os 36 elementos gerados na matriz verificouse correlação significativa em apenas doze (33\%) todas de alta magnitude. 
Tabela 3. Estimativa dos coeficientes de correlação genotípica entre descritores bioquímicos e agronômicos do amendoim

\begin{tabular}{|c|c|c|c|c|c|c|c|c|c|}
\hline \multicolumn{10}{|c|}{ Correlações genéticas } \\
\hline & IQ & IT & AH & PS & CS & 0 & $\mathrm{Vg} / \mathrm{PI}$ & $\mathrm{CH}$ & Pf \\
\hline IQ & 1 & 0.42 & -0.22 & -0.23 & -0.08 & -0.38 & -0.30 & 0.12 & -0.15 \\
\hline IT & & 1 & 0.01 & $-0.64^{*}$ & -0.42 & -0.31 & $-0.77^{\star *}$ & -0.13 & $-0.68^{\star}$ \\
\hline $\mathrm{AH}$ & & & 1 & -0.31 & -0.51 & -0.49 & -0.23 & $0.62^{*}$ & 0.09 \\
\hline PS & & & & 1 & $0.84 * *$ & $0.71^{*}$ & $0.86^{\star \star}$ & -0.32 & $0.72^{\star *}$ \\
\hline CS & & & & & 1 & $0.66^{*}$ & $0.82^{* *}$ & -0.34 & 0.47 \\
\hline 0 & & & & & & 1 & 0.49 & $-0.72^{*}$ & 0.36 \\
\hline $\mathrm{Vg} / \mathrm{PI}$ & & & & & & & 1 & -0.07 & $0.63^{*}$ \\
\hline $\mathrm{CH}$ & & & & & & & & 1 & 0.16 \\
\hline Pf & & & & & & & & & 1 \\
\hline
\end{tabular}

** * Significativo a 0,01 e 0,05, respectivamente, pelo teste $t$

IQ - Inibidor de quimotripsina, IT - Inibidor de tripsina, AH - Altura da haste principal, PS - Peso de 100 sementes, CS - Comprimento de semente, 0 - Teor de óleo na semente; Vg/PI - vagem/ planta, CH - Teor de carboidratos nas folhas, Pf - Teor de proteínas totais nas folhas

A variável PS foi correlacionada com a maioria dos caracteres a ela associada, $\mathrm{CS}\left(0.838^{* *}\right), \mathrm{O}\left(0.712^{\star}\right), \mathrm{Vg} / \mathrm{Pl}\left(0.856^{* *}\right)$ ePT $\left(0.724^{* *}\right)$, porém nenhuma relação foi observada entre os IT e IQ. A propósito, nenhum dos dois tipos de inibidores revelou, com a população deste estudo, qualquer inter-relação com as variáveis estudadas, com exceção das correlações IT x PS $(-0,64)$, IT x Vg/pl $(-0,77)$ e IT x Pf (-0.68), todas com correlação negativa, especialmente esta última, sinalizando que a elevação no teor de proteína nas folhas contribui para reduzir a atividade dos ITs. A priori, este resultado parece ser contraditório considerando-se que ITs também são proteínas; mesmo assim, pode ser explicado levando-se em consideração a grande demanda das proteínas foliares para atender a todas as atividades fisiológicas da cobertura vegetal durante o período de crescimento da planta de modo que, ao se associar metabólitos intrínsecos de sementes com proteínas foliares, a relação tenderia a ser negativa; então, esta característica $(\mathrm{Pf})$ poderia ser utilizada como indicadora de seleção para o caráter ITs sem a necessidade de danificar a semente. No caso de se utilizar como indicador as proteínas de sementes, é de se esperar que a correlação seja positiva e de alta magnitude em razão de ambos os metabólitos estarem presentes no mesmo tecido, o que pode ser comprovado no trabalho de Lima et al. (2004) que verificaram relação positiva entre os teores de $\mathrm{PT}$ nas sementes de feijão com percentual de inibidores de proteases.

\section{Conclusões}

1. Considerando que a predição do teor de IT nas sementes de amendoim se baseia em metodologias destrutivas, é possível estimar este caráter baseando-se no teor de proteínas nas folhas em função de existir correlação negativa e de alta magnitude para ambas as características.

2. Para o presente estudo, esforços para identificação de linhagens de amendoim com tolerância a pragas de grãos armazenados podem ser envidados com as linhagens P20 e P67, que se destacaram para os teores de IT e IQ.

\section{Agradecimentos}

À Rede Nacional de Pesquisa em Agrobiodiversidade e Sustentabilidade Agropecuária - REPENSA (MCT/CNPq/
MEC/CAPES/CT-AGRO/CT-IDRO/FAPS/EMBRAPA) pelo suporte financeiro.

\section{Literatura Citada}

Bland, J. M..; Lax, A. Isolation and characterization of a peanut maturity-associated protein. Journal Agricultural and Food Chemistry, v.48, p.3275-3279, 2000.

Bradford, M. Rapid and sensitive method for the quantitation of microgram quantities of protein utilizing the principle of protein-dye binding. Analytical Biochemistry, v.72, p.248-254, 1976.

Chye, M. L.; Sin, S. F.; Xu, Z. F.; Yeung, E. C. Serine proteinase inhibitor proteins: exogenous and endogenous functions. In Vitro Cellular \& Developmental Biology - Plant, v.42, p.100-108, 2006.

Cruz, C. D. Programa Genes: Análise multivariada e simulação. 1.ed. Viçosa: UFV, 2006. 175p.

De Paola, D.; Blanco, E.; Pierre, C. L.; Sonnante, G. Isolation and characterization of novel variants of BBI coding genes from the legume Lathyrus sativus. Plant Physiology and Biochemistry, v.57, p.45-53, 2012.

Dodo, H. W.; Viquez, O. M.; Maleki, S. J.; Konan, K. N. cDNA clone of a putative peanut (Arachis hypogaea L.) trypsin inhibitor has homology with peanut allergens Ara h 3 and Ara h 4. Journal Agricultural Food Chemistry, v.52, p.14041409, 2004.

Dubois, M.; Gilles, K. A.; Hamilton, J. K.; Rebers, P. A.; Smith, F. Colorimetric methods for determination of sugars and related substances. Analytical Chemistry, v.28, p.350-356, 1956.

Dunaevsky, Y. E.; Elpidina, E. N.; Vinokurov, K. S.; Belozersky, M. A. Protease inhibitors in improvement of plant resistance to pathogens and insects. Molecular Biology, v.39, p.608613, 2005.

Freire, R. M. M.; Suassuna, T. M. F. Potencial do óleo de amendoim como fonte de biodiesel. In: Santos, R. C.; Freire, R. M. M.; Suassuna, T. M. F. Amendoim: o produtor pergunta, a Embrapa responde. Brasília: Embrapa Algodão, 2009. Cap. 13, p.211-220.

Habib, H.; Fazili, K. M. Plant protease inhibitors: a defense strategy in plants. Biotechnology and Molecular Biology Review, v.2, p.68-85, 2007.

Hartl, M.; Giri, A. P.; Kaur, H.; Baldwin, I. T. The multiple functions of plant serine protease inhibitors. Plant Signaling \& Behavior, v.6, p.1009-1011, 2011.

Haq, S. K.; Atif, S. M.; Khan, R.H. Protein proteinase inhibitor genes in combat against insects, pests, and pathogens: natural and engineered phytoprotection. Archives of Biochemistry and Biophysics, v.431, p.145-159, 2004.

Lima, L. M.; Araújo, A. H.; Oliveira, A. S.; Pereira, R. A.; Miranda, M. R. A.; Sales, M. P. Comparative digestibility and the inhibition of mammalian digestive enzymes from mature and immature cowpea (Vigna unguiculata (L.) Walp.) seeds. Food Control, v.15, p.107-110, 2004. 
Lima, L. M.; Morais, A. H. A. Propriedades nutracêuticas do amendoim. In: Santos, R. C.; Freire, R. M.; Lima, L. M. O agronegócio do amendoim no Brasil. 2.ed. Campina Grande: Embrapa Algodão, 2013. Cap.11, p.468-497.

Macedo, M. L. R.; Durigan, R. A.; Silva, D. S.; Marangoni, S.; Freire, M. G. M.; Parra, J. R. P. Adenanthera pavonina trypsin inhibitor retard growth of Anagasta kuehniella (Lepidoptera: Pyralidae). Archives of Insect Biochemistry and Physiology, v.73, p.213-231, 2010.

Martins, P. L. Detecção de inibidores de tripsina em genótipos de amendoim visando controle de pragas de grãos armazenados. Campina Grande: UEPB, 2013. 56p. Dissertação Mestrado

Mosolov, W.; Valueva, T. A. Proteinase inhibitors in plant biotechnology: A review. Applied Biochemistry and Microbiology, v.44, p.233-240, 2008.

Norioka S.; Ikenaka T. Amino acid sequences of trypsinchymotrypsin inhibitors (A-I, A-II, B-I, and B-II) from peanut (Arachis hypogaea): A discussion on the molecular evolution of legume Bowman-Birk type inhibitors. Journal Biochemistry, v.94, p. 589-599, 1983.

Norioka, S.; Ikenaka, T. Inhibition mechanism of a peanut trypsin-chymotrypsin inhibitor BIII: Determination of the reactive sites for trypsin and chymotrysin. Journal Biochemistry, v.96, p.1155-1164, 1984.

Oliveira, A. S.; Migliolo, L.; Aquino, R. O.; Ribeiro, J. K. C.; Macedo, L. L. P.; Bemquerer, M. P.; Santos, E. A.; Kiyota, S.; Sales, M. P. Two kunitz-type inhibitors with activity against trypsin and papain from Pithecellobium dumosum Seeds: purification, characterization, and activity towards pest insect digestive enzyme. Protein \& Peptide Letters, v.16, p.1526-1532, 2009.

Oliveira, A. S.; Pereira, L. M.; Lima, L.M.; Morais, A. H. A.; Melo, F. R.; Franco, O. L.; Bloch Júnior, C.; Sá, M. F. G. de; Sales, M. P. Activity toward bruchid pest of a kunitz-type inhibitor from seeds of the algaroba tree (Prosopis juliflora D.C.). Pesticide Biochemistry and Physiology, v.72, p.122132, 2002.
Pereira, R. A.; Jiménez, A. V.; Magalhães, C. P.; Prates, M. V.; Melo, J. A.; Lima, L. M.; Sales, M. P.; Tempel Nakasu, E. Y.; Silva, M. C.; Sá, M. F. G. de. Effect of a bowman-birk proteinase inhibitor from Phaseolus coccineus on Hypothenemus hampei gut proteinases in vitro. Journal Agricultural Food Chemistry, v.55, p.10714-10719, 2007.

Pereira, W. P.; Melo Filho, P. A.; Albuquerque, M. B.; Nogueira, R. J. M. C.; Santos, R. C. Mudanças bioquímicas em genótipos de amendoim submetidos a deficit hídrico moderado. Revista Ciência Agronômica, v.43, p.766-773, 2012.

Santos, R. C.; Rego, G. M.; Santos, C. A. F.; Melo Filho, P. A.; Silva, A. P. G.; Gondim, T. M. S.; Suassuna, T. F. Recomendações técnicas para o cultivo do amendoim em pequenas propriedades agrícolas do Nordeste brasileiro. Campina Grande: Embrapa Algodão, 2006. 7p. Embrapa Algodão. Circular técnica, 102

Santos, R. C.; Rego, G. M.; Silva, A. P. G.; Vasconcelos, J. O. L.; Coutinho, J. L. B.; Melo Filho, P. A. Produtividade de linhagens avançadas de amendoim em condições de sequeiro no Nordeste brasileiro. Revista Brasileira de Engenharia Agrícola e Ambiental, v.14, p.589-593, 2010.

Serquiz, A. C. Efeito sacietogênico de um novo inibidor de tripsina da paçoca do amendoim com aumento plasmático de colecistocinina (CCK). Natal: UFRN, 2012. 97p. Dissertação Mestrado

Silva, F. C.; Silva, F. C.; Alcazar, A.; Macedo, L. L.; Oliveira, A. S.; Macedo, F. P.; Abreu, L. R.; Santos, E. A.; Sales, M. P. Digestive enzymes during development of Ceratitis capitata (Diptera:Tephritidae) and effects of SBTI on its digestive serine proteinase targets. Insect Biochemistry and Molecular Biology, v.36, p.561-569, 2006.

Zavala, J. A.; Patankar, A. G.; Gase, K.; Hui, D.; Baldwin, I. T. Manipulation of endogenous trypsin proteinase inhibitor production in Nicotiana attenuata demonstrates their function as antiherbivore defenses. Plant Physiology, v.134, p.1181-1190, 2004. 